\title{
Teorias de Aprendizagem e Arquiteturas Pedagógicas: A Relação entre Ambas no Ensino a Distância
}

\author{
Leonardo da Silva Morais*1
}

\begin{abstract}
1 Mestre em Gestão e Estratégia - Professor-tutor, Coordenação de Educação a Distância/Departamento de Estratégia de Gestão/Centro de Ciências Jurídicas e Políticas/Universidade Federal do Estado do Rio de Janeiro. Av. Pasteur, 296 - Urca - Rio de Janeiro - RJ - Brasil. leonsysad@yahoo.com.br
\end{abstract}

\section{Resumo}

A pesquisa teve como objetivo principal apresentar como as principais teorias de aprendizagem se adaptam às modalidades de ensino a distância, sendo os objetivos secundários identificar e apresentar as características das doutrinas utilizadas na elaboração das arquiteturas pedagógicas no EaD. Em função de ser esse o canal de maior expansão e que frequentemente se atualiza das ferramentas tecnológicas utilizadas pela sociedade, o estudo foi realizado no EaD on-line. Foram abordadas as teorias de aprendizagem mais conhecidas e exploradas nos trabalhos de EaD, sendo elas: behaviorista, cognitivista, sociocultural e construtivista. As arquiteturas pedagógicas estudadas foram: a de estudo de caso ou resolução de problema, aprendizagem incidente e de ação simulada. Após estudo das teorias pedagógicas e modelos de arquitetura apresentados, foi possível estabelecer uma relação direta entre um e outro, além de identificar variações: na atuação do papel do professor e no modo operante de como ocorre o ensino a distância para o alcance do propósito final. O resultado final confirma a suposição inicial da pesquisa de que não existe uma teoria específica para o EaD, e que tudo vai variar de acordo com o propósito do curso.

Palavras-chave: Teoria de aprendizagem; Arquitetura de aprendizagem; Ensino a distância. 


\title{
Learning Theories and Architectures Pedagogical: The Relationship Between Both in Distance Learning
}

\begin{abstract}
The research mainly aimed to present how the main learning theories adapt to teaching from a distance. The secondary objective is to identify and present characteristics of the doctrines used in preparing the pedagogical architectures in e-learning courses. The study was conducted online because e-learning is the largest expanded and connected channel that frequently updates technologic tools used by society. In this work, the best known and explored learning theories in the works distance e-learning have been addressed,, namely: behavioral, cognitive, and sociocultural constructivist. The pedagogical architectures studied were: case study or problem solving, learning incident, and simulated action. After studying the pedagogical theories and architectural models presented, it was possible to establish a direct relationship between them, and identify variations such as the role of the teacher in e-learning for reaching the final purpose. The final result confirms the initial assumption of the research that there is no specific theory for e-learning and that everything will vary according with the purpose of the course. The growing demand for education courses in e-learning and the popularization of internet access will allow new architectural models pedagogical to be created in the future, but always with the support of some learning theory. It is believed that with the passage of time and an increasing empirical basis, there can be more exploration of other theories.
\end{abstract}

Keywords: Learning theory; Learning architecture; Distance learning. 


\section{Introdução}

O desenvolvimento tecnológico tem sido uma característica que acompanha a evolução da espécie humana. Motivadas pelo avanço capitalista, as pessoas e empresas procuram, por meio dos avanços tecnológicos, obterem ganhos em escala com aumento da produtividade e redução de custos.

Entretanto, mesmo com todo o progresso, o homem ainda não conseguiu alterar uma variável fundamental que é o tempo. Logo, o tempo passou a pertencer aos indicadores de redução de uma determinada tarefa ou serviço a ser produzido.

A competição gerada pelo capitalismo faz com que cada vez mais as pessoas incorporem novas ferramentas tecnológicas ao cotidiano. Não se trata de opção, mas sim de necessidade de adequação e sobrevivência na atual realidade em que vivemos.

A tecnologia sob o álibi de redução de custos e ganho de tempo penetra em todos os segmentos e serviços da sociedade. Onde existir a participação humana, haverá a presença da tecnologia, seja no simples processo de compra no mercado com uso do cartão de crédito ou em uma guerra com mísseis programados para interceptar bombas aéreas.

Sob a ótica dos argumentos acima, mais recentemente a tecnologia tem amadurecido num segmento muito sensível da sociedade, que é a educação. Sob vários dogmas e estritamente conservador, observou-se que o setor tem apresentado resistência e dificuldade para assimilação de novas tecnologias.

O uso de novas ferramentas tecnológicas no modelo de aula tradicional (presencial) tem sido uma constante, principalmente, nos últimos 15 anos. A utilização de slides com projetores nas apresentações de trabalhos em grupo e seminários, o envio de trabalhos por meio de correio eletrônico dos discentes e o lançamento das notas (avaliações) nas plataformas virtuais por parte dos docentes foram etapas superadas por boa parte do setor educacional.

Talvez a maior das alterações no segmento da educação ocorra na alteração do modelo de aula, com a inserção do ensino a distância (EaD) on-line, pois durante anos a sociedade foi doutrinada a associar conhecimento à sala de aula. Entendo que o EaD é uma quebra de paradigma aos conceitos tradicionais de ensino na história da humanidade, pois nesse modelo há necessidade de uma maior interação com a realidade. O problema disciplinar é o seu modus operandi constituído em desconexão com a vida (Carvalho, Nevado \& Menezes, 2005, p. 354). 
Acredito que o momento atual seja o mais difícil, por ser o de adaptação ao EaD e, ao mesmo tempo, por não termos pessoas (docentes e discentes) familiarizados com essa nova realidade. Várias são as dificuldades, desde o modelo mental de plano de aula do professor tradicional até o gerenciamento do tempo por parte dos alunos.

Este trabalho adotou a figura do tutor como sendo a do discente no EaD, por considerar que é esse o indivíduo que interage e conduz o conhecimento entre o material e o aluno. O tutor, denominação geralmente atribuída ao professor on-line, e a competência tecnológica, apesar de não ser a principal, são essenciais para que ele possa agir com naturalidade, agilidade e aptidão no ambiente virtual repleto de recursos tecnológicos que irá utilizar (Reis, 2005, p. 4).

A definição de tutor como professor é importante, vista a necessidade de competências e habilidades que o profissional deve apresentar. O tutor no EaD é antes de tudo um professor, e chamá-lo de tutor é reduzir o seu papel pedagógico (Ferreira \& Lobo, 2005, p. 2626).

Para Carvalho, Nevado e Menezes (2005), os professores são imprescindíveis para criarem e reinventarem as arquiteturas pedagógicas, bem como trazem consigo bagagem disciplinar fundamental à proposição de novas didáticas e à orientação dos estudantes. O papel do discente continuará a existir, entretanto, com necessidade de novas práticas.

Ferreira e Lobo (2005) entendem que dentre as necessidades, é importante que o profissional seja um pesquisador, criativo, aberto ao diálogo e atento às construções dos alunos, proporcionando-Ihes condições de realizar atividades criativas, apresentando novas referências e oportunizando momentos de reflexão que auxiliem a sua compreensão. As habilidades e competências a serem desenvolvidas são similares às exercidas pelo professor da aula presencial.

Mesmo com todo o avanço tecnológico, não há como desconsiderar as doutrinas de aprendizagem utilizadas no ensino até hoje. Pelo contrário, os conceitos devem ser entendidos e usados no EaD para validação e fixação dos conhecimentos.

Diante do exposto, surge o problema de pesquisa do artigo: como as principais teorias de aprendizagem se adaptam às propostas de cursos ofertados no EaD?

Para que não houvesse uma generalização no entendimento do processo de EaD, em função de quanto são distintas as propostas do conteúdo a ser explorado entre educador e educado, optou-se por trabalhar os diferentes objetivos de quando se procura o EaD e as principais teorias de aprendizagem. A incorporação das tecnologias nos 
"desenhos" globais de formação virtual não garante, por si só, a efetividade dos resultados, devendo estar sustentada por uma teoria de aprendizagem que justifique esse "desenho" e o delimite (Gomez, 2001).

Além do capítulo de introdução, o texto apresenta as seguintes seções: metodologia, referencial teórico, modalidade de ensino no EaD, resultados e considerações finais.

A pesquisa teve como objetivo principal apresentar como as principais teorias de aprendizagem se adaptam às modalidades de ensino a distância. Os objetivos secundários foram identificar e apresentar as características das doutrinas utilizadas na elaboração das arquiteturas pedagógicas no EaD. A suposição inicial é que as diferentes teorias de aprendizagem suportam as modalidades do EaD quando respeitado o propósito final proposto.

\section{Metodologia}

Para este trabalho, a pesquisa considerou o EaD on-line, em função de ser esse o canal de maior expansão e que frequentemente se atualiza e faz uso das ferramentas tecnológicas utilizadas pela sociedade. A educação on-line está relacionada ao uso da internet como meio para a publicação de material didático-pedagógico para a realização de cursos, comunicação com (e entre) estudantes, etc. (Lencastre \& Araújo, 2008, p. 2).

A coleta de dados ocorreu por meio de pesquisas documentais e bibliográficas disponíveis na internet. Os artigos utilizados como fonte foram selecionados a partir de consulta das palavras "teoria de aprendizagem" e "ensino a distância", no sistema de busca do periódico CAPES e no site de busca "Google Acadêmico", sendo escolhidos aqueles de maior relevância (os mais citados ou os que mais apareceram).

Diante dos dados coletados, foi possível estabelecer uma conexão entre o referencial teórico que fundamentou as teorias de aprendizagem e os cursos demandados no EaD, sendo apresentadas em seguida as teorias que mais se adequam aos cursos demandados pela sociedade.

A técnica para análise de dados identificada como apropriada para o trabalho foi a interpretativa com base nas fontes selecionadas. O paradigma interpretativo exige esforços específicos do pesquisador, incluindo as questões que ele propõe e as interpretações que ele traz para elas (Denzin \& Lincoln, 2006). 
O EaD on-line é um processo que progride paralelamente com o avanço da tecnologia, logo, se o compararmos com a forma de ensino presencial, podemos afirmar que está apenas engatinhando em função do pouco tempo de sua utilização. Assim, o trabalho apresenta limitações quanto ao número de artigos selecionados, que tratam das teorias de aprendizagem para o EaD, em função de termos um universo pequeno de trabalhos acadêmicos produzidos se confrontado ao ensino tradicional.

Em relação ao quantitativo e às mais variadas classificações das teorias de aprendizagem, buscaram-se aquelas que mais se aproximam das utilizadas no EaD de acordo com a seleção do material coletado. As teorias exploradas foram: behaviorismo, cognitiva, sociocultural e construtivista.

Para Gil (2002), no que se refere à subjetividade apresentar uma limitação mais crítica, esse aspecto é mais ou menos presente em toda investigação social. Existe um consenso na literatura de que todos os métodos de pesquisa possuem limitações. Todavia, essas limitações são provenientes da empiria e devem ser minimizadas. Como forma de atenuá-las, foi realizada a triangulação de dados (bibliográfico, documental e empírico) para maior confiabilidade nos resultados apresentados posteriormente.

Por fim, na última etapa do trabalho, são expostas as considerações finais que dispõem sobre os resultados apresentados, além de versarem sobre perspectivas futuras e mencionarem possibilidades de aprofundamento na temática do assunto.

\section{Referencial teórico}

Aqui são abordadas as teorias de aprendizagem mais conhecidas e exploradas nos trabalhos de EaD. São elas: behaviorista, cognitivista, sociocultural e construtivista.

\subsection{Teoria behaviorista}

Uma definição resumida foi dada por Reinaldo, Camacho e Reis (2011, p.820), ao afirmarem que "a teoria behaviorista utiliza-se de uma sequência de regras simplistas e monolíticas para produzir ações que direcionem o comportamento do aprendiz a reagir ao ambiente". Essa teoria é caracterizada pela objetividade e simplificação do processo.

Para Ostermann e Cavalcanti (2010), o behaviorismo tem caráter empirista, sendo uma teoria muito baseada em estímulo-resposta (E-R). Nela há uma indicação de que o 
comportamento humano é previsível. A aprendizagem aconteceria pela imitação e formação de hábitos em decorrência de excesso de treinos ou reações originadas pelo ambiente (Reinaldo, Camacho \& Reis, 2011, p. 820).

Ainda de acordo com Ostermann e Cavalcanti (2010), os métodos de ensino consistem nos procedimentos e técnicas necessários ao arranjo e controle das condições ambientais, que asseguram a transmissão/recepção de informações. Para os autores, há possibilidade do controle do que é feito pelo processo de resposta, mediante quantidade de repetições de determinado movimento.

De acordo com os estudos de Thorndike ${ }^{1}$, explorado por Ostermann e Cavalcanti (2010), cabe ao professor propor aos alunos a prática das respostas desejadas por meio de muitos exercícios que fortalecem as conexões a serem aprendidas e, ao mesmo tempo, descontinuam a prática de conexões indesejáveis. O quantitativo de repetições está proporcionalmente relacionado ao desempenho do usuário.

Avançado o processo de behaviorismo, Thorndike e o teórico Skinner², entenderam que a aprendizagem está relacionada a uma questão de modificação do desempenho: o bom ensino depende de organizar eficientemente as condições estimuladoras, de modo que o aluno saia da situação de aprendizagem diferente de como entrou, sendo o ensino um processo de condicionamento por meio do uso de reforçamento das respostas que se quer obter (Ostermann \& Cavalcanti, 2010, p. 13).

De acordo com Reis (2005), no início do EaD, a teoria de aprendizagem mais utilizada era a teoria behaviorista, que considera as respostas dos alunos sempre passíveis de serem reforçadas por algum sistema de premiação, o que causava enorme dependência do professor, pois a base de treinos e repetições era determinada pelos professores.

Para Ostermann e Cavalcanti (2010), o professor deve, primeiramente, modelar respostas apropriadas aos objetivos instrucionais e, acima de tudo, conseguir o comportamento adequado pelo controle do ensino (por meio da tecnologia educacional).

Corroboram do mesmo entendimento Reinaldo, Camacho e Reis (2011), que afirmam que o aprendiz não inventa ou desenvolve algo, somente aprende se, e somente se, executar os conteúdos que o professor determinar. Para os referidos autores, o aprendiz não possui qualquer conhecimento extensivo, somente o conhecimento básico inserido a priori pelo especialista do conhecimento - o professor. 


\subsection{Teoria cognitivista}

A teoria cognitivista possui como característica o trabalho na elaboração de um processo mental desenvolvido pelo receptor por meio de uma realidade apresentada. Ela enfatiza o processo de cognição por meio do qual a pessoa atribui significados à realidade em que se encontra (Ostermann \& Cavalcanti, 2010, p.19).

No entendimento de Alves, Cabral e Costa (2003), as pessoas assimilam o conhecimento por intermédio de tarefas construtivas, pois a meta dessa abordagem é incentivar a criatividade e motivar a aprendizagem por meio da atividade. Ou seja, o crescimento está em não apenas repetir as tarefas apresentadas, mas criar a partir do que foi observado. Assim, a aprendizagem significativa é um modelo de processo pelo qual uma nova informação é relacionada de maneira simbólica via processos semânticos (Reinaldo, Camacho \& Reis, 2011, p. 821).

Corroboram do mesmo entendimento, os pesquisadores Ostermann e Cavalcanti (2010), pois para eles a preocupação é com o processo de compreensão, transformação, armazenamento e uso da informação envolvido na cognição e procura de regularidades nesse processo mental. A ideia principal é que o produto desenvolvido pelo receptor seja diferente do apresentado pelo emissor. A ênfase dessas abordagens de aprendizagem está na recepção, armazenamento, organização, integração e posterior distribuição das ideias no cérebro do aprendiz (Reinaldo, Camacho \& Reis, 2011, p. 821).

Pela teoria cognitiva, as informações disponibilizadas ao receptor servem como "ponto de partida" de algo que será desenvolvido, logo, para a melhor construção das ideias cognitivas, acredita-se que quanto mais diferentes forem os aspectos visualizados melhores serão os produtos finais. No conteúdo exposto, o aprendiz deve ter a oportunidade de ver o mesmo tópico mais de uma vez em diferentes níveis de profundidade e em diferentes modos de representação (Ostermann \& Cavalcanti, 2010, p. 20).

Um dos maiores teóricos do cognitivismo, Piaget $^{3}$, argumentava que para que o aluno desenvolvesse determinado assunto, ele deveria sair da zona de conforto de tal modo que pudesse se desenvolver a partir de onde ele se situava. Para Ostermann e Cavalcanti (2010), ensinar é provocar o desequilíbrio, mas este não pode ser tão grande a ponto de não permitir a equilibração majorante que levará a um novo equilíbrio. Concluem os autores que se a assimilação de um tópico requer um grande desequilíbrio, o professor deve introduzir passos intermediários para reduzi- lo. 
De acordo com o trabalho de Ostermann e Cavalcanti (2010), outro grande teórico do cognitivismo foi Ausubel ${ }^{4}$, que apresentou as quatro etapas para o desenvolvimento exitoso da teoria.

10 Determinar a estrutura conceitual e proposicional de matéria do ensino, organizando os conceitos e princípios hierarquicamente.

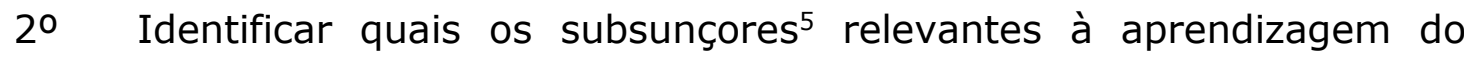
conteúdo a ser ensinado, que o aluno deverá ter na sua estrutura cognitiva para aprender significativamente.

30 Dentre os subsunçores relevantes, quais os que estão disponíveis na estrutura cognitiva do aluno.

40 Finalmente, ensinar utilizando recursos e princípios que facilitem a assimilação da estrutura da matéria de ensino por parte do aluno e organização de suas próprias estruturas cognitivas nessa área de conhecimentos por meio da aquisição de significados claros, estáveis e transferíveis.

Por não fazer distinção entre os métodos de ensino (presencial e EaD), acreditase que a estrutura acima é válida em qualquer das situações desde que existam habilidades do professor. As competências científica e pedagógica do professor ainda são fundamentais para um bom desempenho do aluno no processo educacional como um todo, independente do meio em que está atuando, numa sala de aula presencial ou virtual (Reis, 2005, p. 9).

\subsection{Teoria sociocultural}

A teoria sociocultural está relacionada a uma participação maior do aprendiz, que deixa de ser apenas ouvinte e passa a ser também emissor para a contribuição do aprendizado coletivo de forma a linear o conhecimento por meio da interação entre os alunos. O desenvolvimento humano está definido pela interiorização dos instrumentos e signos; pela conversão dos sistemas de regulação externa em meios de autorregulação (Ostermann \& Cavalcanti, 2010, p. 27).

De acordo com Ostermann e Cavalcanti (2010), a arquitetura funcional proposta por Vygotsky 6 é um modelo variável na ontogênese, mas cuja forma está definida 
precisamente pela interação e pela cultura. Dessa forma, cada momento de aprendizagem será distinto de outro em função dos pressupostos carregados pelos participantes e também pelo intelecto de cada um dos envolvidos.

O foco está no desenvolvimento do aprendiz como indivíduo social e a sua evolução cognitiva depende do ambiente, dos conhecimentos desenvolvidos (símbolos de seu conhecimento) durante a interação entre si e o meio, o objeto ou as pessoas, levando em consideração o desenvolvimento mental do indivíduo (Reinaldo, Camacho \& Reis, 2011, p. 821).

As informações recebidas são processadas e adaptadas à realidade do próprio indivíduo. Esse recebe os dados oriundos do ambiente sociocultural pelos seus sentidos e os organiza em seu mundo real (Reinaldo, Camacho \& Reis, 2011, p. 821).

Dentre os teóricos que se destacam na teoria sociocultural está o brasileiro Paulo Freire$^{7}$, que teve seus estudos explorados nos trabalhos acadêmicos realizados por Ostermann e Cavalcanti (2010).

Nos círculos de cultura, não existia um programa de conteúdos definidos previamente. Os temas eram debatidos e era o grupo que os estabelecia. Não era o grupo de educadores que desenvolvia o tema. Cabia aos educadores orientar os alunos enriquecendo os debates e propondo temas secundários que impulsionavam o processo educativo. Esses temas tornavam mais claro e ilustravam o tema inicialmente estabelecido (Ostermann \& Cavalcanti, 2010, p. 30).

Nesse contexto, o certo ou errado são definidos de acordo com os aspectos culturais, sendo discutidos e enraizados mediante o senso comum. O erro do aprendiz é definido como algo que não existe; é um desvio do padrão de um raciocínio lógico desenvolvido sobre algo que o direcionou àquele resultado e que não atingiu uma resposta aproximada da imitação de seu supervisor (Reinaldo, Camacho \& Reis, 2011, p. 820).

Na teoria sociocultural, o professor deixa de atuar como o personagem central da disseminação do conhecimento; sua função passa a ser de mediador, tutor ou gerenciador dos processos de ensino por meio da interação social.

Ao invés de apenas apresentar os diversos itens do kit de ferramentas da ciência oficial e esperar que os alunos os dominem espontaneamente, o ensino de ciência deveria oferecer mais oportunidades para os alunos atuarem com essas ferramentas culturais, seja através de debates em grupo, resolução de problemas ou atividades experimentais nos 
laboratórios didáticos e de informática (Ostermann \& Cavalcanti, 2010, p. 36).

\section{Modalidade de ensino no EaD}

Os cursos disponíveis no EaD são elaborados sobre um desenho a fim de atender a um propósito específico. Essa estrutura é chamada de arquitetura pedagógica ${ }^{8}$. $\mathrm{Na}$ verdade, as arquiteturas pedagógicas têm componentes informativos e propositivos, pois a estrutura é uma forma com caminhos ora mais abertos, ora mais fechados. (Carvalho, Nevado \& Menezes, 2005, p. 354).

Dentro do conceito da arquitetura pedagógica apresentada, abordamos apenas o propósito final e como é apresentado no cotidiano. Optou-se por deixar uma linguagem tecnocrática e conceitual, selecionar três modelos de arquitetura pedagógica, apresentados nos trabalhos de Carvalho, Nevado e Menezes (2010), e exemplificar por meio de cursos disponíveis na rede mundial de computadores, como segue abaixo.

\subsection{Arquitetura de estudo de caso ou resolução de problema}

Nesse tipo de desenho, a solução está nas respostas dos próprios usuários. Em geral, a construção é coletiva. O caso ou problema tem sentido para alguém que necessita saber isto (algo definido pelo sujeito ou pelo grupo). Tal necessidade não se põe a priori, esta é criada pelo próprio sujeito ou é mobilizada por outro ou por situações. (Carvalho, Nevado \& Menezes, 2005, p. 356)

Essa modalidade de ensino permite a construção do aprendizado em rede com participação de vários alunos com um propósito único. Nessa modalidade, é permitido que alunos de diferentes regiões possam explorar distintas realidades e, como consequência, enriquecer trabalhos de diferentes naturezas como, por exemplo, os artigos científicos.

\subsection{Arquitetura de aprendizagem incidente}

De acordo com Carvalho, Nevado e Menezes (2005), é uma forma de aprendizagem derivada, particularmente, em relação a alguma informação impreterível 
ou cansativa. Continuam os autores: "afinal, nem tudo o que se necessita saber é realmente interessante" (Carvalho, Nevado \& Menezes, 2005, p. 357). Busca-se de forma criativa induzir o receptor a chegar ao resultado desejado pelo emissor.

A intenção é criar arquiteturas educacionais com tarefas que podem não ser tão interessantes, mas que são necessárias à realização de um objetivo maior, de modo que o resultado final é positivo e desejado (Carvalho, Nevado \& Menezes, 2005, p. 357).

Nesse tipo de arquitetura, estão os cursos de modalidades que trabalham com níveis dependentes de conhecimento com etapas obrigatoriamente subsequentes. Como exemplo, temos os cursos de idiomas que, geralmente, classificam o estágio do aluno como básico, intermediário e avançado, sendo necessário seguir um caminho obrigatório para se chegar ao objetivo final, que é ter o domínio do idioma.

\subsection{Arquitetura de ação simulada}

Para esse tipo de arquitetura, entende-se que a repetição e a simulação de uma ação que já ocorre são as melhores formas de se aprender. O pressuposto dessa arquitetura assenta-se na ideia de que o melhor meio de aprender a realizar uma atividade é fazê-la ou aprender a fazer fazendo (Carvalho, Nevado \& Menezes, 2005, p. 358).

Nessa categoria de arquitetura, há um quantitativo de modalidades bastante variado. Vejamos alguns exemplos: cursos voltados para concursos públicos que trabalham com simulações de provas; simuladores de voos em que o indivíduo opera em condições parecidas com as vivenciadas na realidade; ou até mesmo videoaulas de culinária, em que o receptor procura repetir os passos seguidos pelo emissor.

\section{Resultados e considerações finais}

Após estudo das teorias pedagógicas e modelos de arquitetura apresentados, foi possível estabelecer uma relação direta entre um e outro, além de identificar variações no papel do professor e no modo operante como ocorre o ensino para se chegar a um propósito final. 
Tabela 1: Síntese operacional das teorias de aprendizagem e arquitetura pedagógica.

\begin{tabular}{c|c|c|c|c}
\hline $\begin{array}{c}\text { Teoria de } \\
\text { aprendizagem }\end{array}$ & $\begin{array}{c}\text { Arquitetura } \\
\text { pedagógica }\end{array}$ & $\begin{array}{c}\text { Papel do } \\
\text { professor }\end{array}$ & Como ocorre & Propósito final \\
\hline Behaviorista & Ação simulada & Indutor & $\begin{array}{c}\text { Simulação das } \\
\text { ações }\end{array}$ & $\begin{array}{c}\text { Repetir os atos da } \\
\text { realidade }\end{array}$ \\
\hline Cognitivista & $\begin{array}{c}\text { Aprendizagem } \\
\text { incidente }\end{array}$ & Condutor & $\begin{array}{c}\text { Ensinamento em } \\
\text { cascata }\end{array}$ & $\begin{array}{c}\text { Alcançar o objetivo } \\
\text { final estabelecido } \\
\text { pelo professor }\end{array}$ \\
\hline Sociocultural & $\begin{array}{c}\text { Estudo de caso ou } \\
\text { resolução de } \\
\text { problema }\end{array}$ & Mediador & $\begin{array}{c}\text { Desenvolvimento } \\
\text { por meio do } \\
\text { coletivo }\end{array}$ & $\begin{array}{c}\text { Consenso da } \\
\text { maioria na busca } \\
\text { pela solução }\end{array}$ \\
\hline
\end{tabular}

Fonte: Elaboração própria (2014).

Ao analisar a tabela acima, foi possível chegar às considerações a seguir.

- $\quad$ Cada teoria de aprendizagem interage com um modelo de arquitetura pedagógico que, por consequência, impacta numa determinada postura da atuação do professor para que se alcance o propósito final.

- $\quad$ Não existe uma teoria de aprendizagem uniforme para o ensino a distância, pois dependendo do propósito final haverá necessidade de adequações na arquitetura pedagógica e na teoria de aprendizagem que a suportará.

- $\quad$ O papel do professor varia de acordo com a necessidade do curso e com a teoria de aprendizagem a ser utilizada. Logo, o profissional, mesmo que atue no EaD num determinado modelo de arquitetura, deverá se adaptar à metodologia utilizada de acordo com o propósito do curso.

- $\quad$ Por fim, pela inexistência de um modelo de teoria único que se adapte ao EaD, todos são válidos mediante o propósito final, não sendo um modelo melhor ou pior do que o outro.

Assim, o trabalho alcançou o objetivo principal, que foi apresentar como as principais teorias de aprendizagem se adaptam às modalidades de ensino a distância, e confirmou a suposição inicial de que não existe uma teoria única para o desenvolvimento das modalidades no EAD.

Acredito que com o passar do tempo e, consequentemente, o aumento da base empírica, outras teorias possam ser mais exploradas. A crescente demanda por cursos em EaD e a popularização do acesso à internet permitem imaginar que novos modelos 
de arquitetura pedagógica sejam criados no futuro, mas sempre com o suporte de alguma teoria de aprendizagem.

\section{Notas}

1 A pesquisa de Thorndike (1914) revela que a mente não é uma rede complexa de capacidades gerais como observação, atenção, memória, julgamento, etc., e sim um grupo de capacidades específicas, em que cada uma independe da outra e se desenvolve de forma independente (Gomes, 2006).

2 Segundo Skinner, a ciência psicológica - e também o senso comum - costumava, antes do aparecimento do behaviorismo, apelar para explicações baseadas nos estados subjetivos por causa da dificuldade de verificar as relações de condicionamento operante - ou seja, todas as circunstâncias que produzem e mantêm a maioria dos comportamentos dos seres humanos (...) No comportamento operante (de Skinner), o ambiente é modificado e produz consequências que agem de novo sobre ele, alterando a probabilidade de ocorrência futura semelhante (Pedrassoli, 2014).

3 Constata-se que boa parte dos comentadores da obra de Piaget afirma que a inteligência é originariamente de natureza individual e que, portanto, a socialização seria o efeito de um processo de evolução cognitiva (Lajonquière, 1997).

${ }^{4}$ A teoria da assimilação de David Paul Ausubel, ou teoria da aprendizagem significativa, é uma teoria cognitivista e procura explicar os mecanismos internos que ocorrem na mente humana com relação ao aprendizado e à estruturação do conhecimento (Cruz, 2011).

5 Para Ausubel, subsunçores não são o relacionamento com qualquer aspecto da estrutura cognitiva, mas sim com conhecimentos especificamente relevantes (Moreira, 1997).

${ }^{6}$ No Brasil, o trabalho foi conhecido por meio do livro "A formação social da mente" em 1984. Para Vygotsky, as características tipicamente humanas não estão presentes no indivíduo a partir de seu nascimento nem tampouco são simples resultados das pressões 
do meio externo. São resultados da interação dialética do homem e seu meio sociocultural (Gomes, 2006).

$7 \mathrm{O}$ aprendizado do ensinante ao ensinar se verifica à medida que o ensinante, humilde, aberto, se ache permanentemente disponível a repensar o pensado, rever-se em suas posições; em que procura se envolver com a curiosidade dos alunos e dos diferentes caminhos e veredas, que ela os faz percorrer (Freire, 2001).

8 Arquiteturas pedagógicas são estruturas de aprendizagem realizadas a partir da confluência de diferentes componentes: abordagem pedagógica, software educacional, internet, inteligência artificial, educação a distância, concepção de tempo e espaço. (Carvalho, Nevado \& Menezes, 2005).

\section{Referências bibliográficas}

Alves, D. G. , Cabral, T. D. \& Costa, R. M. E. M. (2013). Ambientes Virtuais para Educação a Distância: uma estrutura de classificação e análise de casos. Cadernos do IMESérie Informática, 14, 54-63. Disponível em http://www.epublicacoes.uerj.br/index.php/cadinf/article/viewFile/6616/4731

Carvalho, M. J. S., Nevado, R. A. D., \& Menezes, C. S. D. (2005). Arquiteturas pedagógicas para educação a distância: concepções e suporte telemático. Anais do Simpósio Brasileiro de Informática na Educação, 1(1), 351-360. Disponível em http://br-ie.org/pub/index.php/sbie/article/viewFile/420/406

Cruz, C. C. (2011). A teoria cognitivista de Ausubel. Archivo Del Portal de Recursos para Estudiantes. Acesso em 12 de junho de 2014. Disponível em http://www.robertexto.com/archivo3/a_teoria_ausubel.htm

Denzin, N. K. \& Lincoln, Y. S. (2006). O planejamento da pesquisa qualitativa: teorias e abordagens. Porto Alegre: Art.

Falkembach, G. A. M. (2005). Concepção e desenvolvimento de material educativo digital. RENOTE - Revista Novas Tecnologias Educacionais. Disponível em http://www.cinted.ufrgs.br/renote/maio2005/artigos/a23 materialeducativo.pdf

Ferreira, S. D. L., \& Lôbo, V. I. T. (2005). De Tutor a Professor On-Line: Que Sujeito é Esse?. Anais do Workshop de Informática na Escola 1(1), 2621-2629. Disponível em http://www.br-ie.org/pub/index.php/wie/article/view/840

Freire, P. (2001). Carta de Paulo Freire aos professores. Instituto de Estudos Avançados da Universidade de São Paulo, 15(42), 259-268. Disponível em http://www.br- 
Gil, A. C. (2002). Como elaborar projetos de pesquisa. 4a Ed. São Paulo: Atlas.

Gomes, L. C. G. (2006). A teoria sócio-histórica na construção do conhecimento: uma contribuição para o ensino de design. Revista Design em Foco, 3(1), 81-94. Disponível em http://www.redalyc.org/pdf/661/66130107.pdf

Lajonquière, L. D. (1997). Piaget: notas para uma teoria construtivista da inteligência. Versão corrigida e aumentada do texto: Piaget: intelligence et interaction sociale apresentado nas sessões de comunicação oral da IInd Conference for SocioCultural Research, Université de Genève. Disponível em http://www.scielo.br/scielo.php?pid=S0103$\underline{65641997000100008 \& \text { script }=\text { sci } \text { arttext\# } 1 \text { not }}$

Lencastre, J. A., \& Araújo, M. J. (2008). Educação On-line: uma introdução. E-activity and learning technologies: the proceedings of the IASK. p. 306-312. Disponível em

http://sigarra.up.pt/fpceup/pt/publs pesquisa. show publ file?pct gdoc id=483 $\underline{7}$

Moreira, M. A. (1997). Aprendizaje significativo: un concepto subyacente. Actas Encuentro Internacional sobre el aprendizaje significativo. (pp. 19-44) Burgos, Espanha. Disponível em http://www.if.ufrgs.br/ moreira/apsigsubport.pdf

Ostermann, F., \& Cavalcanti, C. J. H. (2010) Teorias de Aprendizagem. Universidade Federal do Rio Grande do Sul - Instituto de Física. Porto Alegre/RS. Disponível em http://www.ufrgs.br/uab/informacoes/publicacoes/materiais-de-fisica-paraeducacaobasica/teorias_de_aprendizagem_fisica.pdf

Pedrassoli, A. (200X). O Buscador Errante: Skinner. Acesso em 19 de junho de 2014, from http://www.buscadorerrante.com/wp/2009/skinner/

Reinaldo, F., Camacho, R., \& Reis, L. (2011). Arquitetura Híbrida das Teorias de Aprendizagem em Camadas Comportamentais para Ensino à Distância. In: XL IGIP International Symposium on Engineering Education. Santos,SP. Disponível em http://proceedings.copec.org.br/index.php/wccopec/article/view/1428

Reis, I. S. C. L. (2005). Avaliação e o processo de ensino-aprendizagem online. In: $12^{\circ}$ Congresso Internacional de Educação a Distância (120 ABED). Florianópolis/SC. Disponível em http://www.abed.org.br/congresso2005/por/pdf/054tcf3.pdf 